\title{
Fluoride removal from aqueous solution onto activated carbon of Catha edulis through the adsorption treatment technology
}

Jemal Fito ${ }^{1 *}\left(\mathbb{0}\right.$, Hanan Said $^{2}$, Sisay Feleke ${ }^{3}$ and Abebe Worku

\begin{abstract}
Background: Nowadays freshwater quality deterioration and quantity depletion are rapidly increasing across the globe. Especially fluoride polluted groundwater is causing a severe shortage of water supply and public health problem. Hence, this study was designed to investigate the performance of activated carbon produced from the Catha edulis stem for the removal of fluoride from aqueous solution. A C. edulis stem sample was collected from dumping sites of Addis Ababa City and its activation and carbonation processes were performed using $\mathrm{H}_{2} \mathrm{SO}_{4}$ and a high temperature of $600{ }^{\circ} \mathrm{C}$. The experimental study was designed to use a full factorial approach with a $3^{3}$ which were the three factors with the three levels, namely pH (2,7 and 9), contact times (60, 90 and $120 \mathrm{~min}$ ) and adsorbent doses $(0.5 \mathrm{~g}, 1.0 \mathrm{~g}$ and $1.5 \mathrm{~g}$ in $100 \mathrm{~mL})$ at the initial fluoride concentration $30 \mathrm{mg} / \mathrm{L}$ which resulted in 81 experimental runs in triplicates.

Results: The calculated maximum adsorption capacity of $18 \mathrm{mg} / \mathrm{g}$ was found under the Langmuir isotherm, whereas the Freundlich model $\left(R^{2} 0.98\right)$ better fitted the experimental data, which indicated that the adsorption process was multilayer and cooperative. The maximum fluoride removal of $73 \%$ was observed at the optimum condition of adsorbent dose of $1.5 \mathrm{~g}$ in $100 \mathrm{~mL}$ contact time of $60 \mathrm{~min}$ and $\mathrm{pH}$ 2, whereas the predicted value of the fluoride removal of $69 \%$ was calculated under the same experimental condition. Fluoride removal was positive and strongly influenced by the adsorbent dose, whereas the adsorption pH was negatively and weakly impacted on removal.
\end{abstract}

Conclusions: Generally, the performance of activated carbon for the removal of fluoride from aqueous solution is promising. The study also indicated that C. edulis activated carbon is a potential candidate for water treatment technology.

Keywords: Adsorbent, Environmental pollution, Experimental design, Freshwater, Pollutant removal, Water treatment

\section{Background}

Today, freshwater consumption is increasing rapidly at an unexpected rate due to the fast industrial advancement, world population explosion, mechanized agriculture expansion and progress of civilization (Fito et al. 2017a; Fito and Alemu 2019). Basically, in all nations across the globe, access to safe water and sanitation is recognized as a fundamental human right for all (Fito et al. 2019a). However, environmental

\footnotetext{
*Correspondence: fitojemal120@gmail.com

1 Department of Environmental Engineering, Addis Ababa Science

and Technology, P.O.Box 16417, Addis Ababa, Ethiopia

Full list of author information is available at the end of the article
}

crisis, particularly water pollution is a major contributor to water quality deterioration and quantity depletion, which is a global challenge to achieve sustainable development goals. In line with this, about 2.0-2.7 billion people are expected to face severe water shortage challenge by 2050 under current business and water consumption and management practices (UN-Water 2003). Furthermore, an estimated 4.8-5.7 billion people will live in potentially water scarce areas by 2050 (UNWater 2015). It was also reported that water pollution poses serious concerns about human health and environmental risks in many developing countries, particularly those in sub-Sahara, including Ethiopia (Nienie 
et al. 2017; UN Water 2018; Fito et al. 2019b). Fluoride pollution of drinking water is very common, particularly in areas where groundwater is the only source of water supply (Sailaja et al. 2015).

Fluoride exists in rocks in different minerals such as sellaite $\left(\mathrm{MgF}_{2}\right)$, fluorspar $\left(\mathrm{CaF}_{2}\right)$, cryolite $\left(\mathrm{Na}_{3} \mathrm{AlF}_{6}\right)$ and fluorapatite $\left(\mathrm{Ca}_{5}\left(\mathrm{PO}_{4}\right)_{3} \mathrm{~F}\right)$ (Mohapatra et al. 2009). High fluoride concentrations above $4 \mathrm{mg} / \mathrm{L}$ can cause various human health problems, such as dental fluorosis, skeletal fluorosis, decreased birth rates, lower intelligence quotient, thyroid gland injury and neurological disorders (Amalraj and Pius 2017; WHO 2017; Dehghani et al. 2018). Fluorosis is a very common and endemic disease in more than 25 countries worldwide in both developed and developing regions (Jagtap et al. 2012; Amalraj and Pius 2017; Bhattacharya 2017). Generally, the epidemiological studies show that drinking water contributes about $60 \%$ of fluoride ion of the total per capita daily intake (Jagtap et al. 2012). Fluoride concentration $>30 \mathrm{mg} / \mathrm{L}$ in groundwater was reported in many countries and regions, including China, India, Sri Lanka, West Africa (Ghana, Ivory Coast, Senegal), North Africa (Libya, Sudan, Tunisia), South Africa, the East African Rift Valley (Kenya, Uganda, Tanzania, Ethiopia and Rwanda), northern Mexico, and Central Argentina (Joshi et al. 2012). The highest fluoride concentration of $33 \mathrm{mg} / \mathrm{L}$ in drinking groundwater was reported in the Ethiopian section of the East African Rift Valley (Nigussie et al. 2007). However, in recently published papers, the average fluoride concentration in the range of 5 to $26 \mathrm{mg} / \mathrm{L}$ was reported (Mulugeta et al. 2015; Kebede et al. 2016). About 11-14 million people in the Ethiopian rift valley rely on fluoride polluted groundwater (Mulugeta et al. 2015; Kebede et al. 2016).

Fluoride-polluted water treatments have been performed using several purification techniques. The most common fluoride removal methods from drinking water are chemical precipitation, nanofiltration, membrane processes, ion exchange, reverse osmosis, electrocoagulation, and electrodialysis are expensive and thus nonsustainable for developing countries (Fito et al. 2019c). Additionally, these methods require high energy, chemical, operational and capital inputs and advanced technologies. These shortcomings of the various methods of defluoridation prompted researchers to find alternative treatment methods. In comparison with other aforementioned treatment techniques, adsorption of fluoride removal from drinking water is the most appropriate and widely used treatment technique. Flexibility, simplicity of design, relative ease of operation, cost-effectiveness, environmental considerations and production of high water quality are the major advantages of the adsorption treatment technology (Lavecchia et al. 2012; Nure et al. 2017). However, commercially developed activated carbon is a universal adsorbent and very expensive which makes adsorption unsuitable for developing countries.

The development of cost-effective and efficient adsorbent methods is still under investigation. In recent years, the use of inexpensive, easily available adsorbents with high carbon content and low inorganic composition have been used as potential raw material for the preparation of activated carbon. Special attention is given for locally developed adsorbents that are promising raw materials for the removal of contaminants from water and wastewater (Asaithambi et al. 2018). Hence, many studies are focused on adsorbents for fluoride removal from drinking water, such as an alum manufacturing process (Nigussie et al. 2007), alumina in bauxite (Lavecchia et al. 2012), activated alumina (Mulugeta et al. 2015), $\mathrm{CaCl}_{2}$-modified Crocus sativus leaves (Dehghani et al. 2018), fired clay pots (Kofa et al. 2017), bark of Morinda tinctoria (Amalraj and Pius 2017), bark of the Vitex negundo plant (Suneetha et al. 2015), lanthanum-impregnated bauxite (Vardhan and Srimurali 2016), lapsi seed stone (Joshi et al. 2012), Al-Ce hybrid adsorbent (Liu et al. 2010) and iron ore (Kebede et al. 2016). However, researchers are still looking for practical and affordable adsorbents which can be applied at the commercial scale that leads to improving water supply quality in the regions of fluoridesaturated groundwater. Generally, adsorption is considered as an attractive, effective, convenient, easy to apply, simple to design, low cost and environmentally compatible technology (Loganathan et al. 2013).

Khat (Catha edulis), a dicotyledonous evergreen shrub of the family Celastraceae is a plant cultivated for the sedative effect in its leaves. In Ethiopia, C. edulis' stems are disposed of everywhere, especially around the khat market areas, streets and dumpsters. Thus C. edulis' stems are a major contributor to the huge amount of solid waste in larger Ethiopian cities. The use of C. edulis stems as a potential source of activated carbon was explored in this study. Employing this byproduct as an adsorbent for removal of fluoride from the water supply may thus be an environmentally friendly and practical waste conversion method (Fito et al. 2017b). However, very few studies have been conducted so far on the preparation of the activated carbon from C. edulis. Therefore, this study was designed to investigate the performance of activated carbon produced from C. edulis stems for the removal of fluoride from aqueous solution. Additionally, the experimental study was designed to use full factorial approach with a $3^{3}$, which were the three levels of the three independent variables, namely: $\mathrm{pH}(2,7$ and 9), contact time (60, 90 and $120 \mathrm{~min})$ and adsorbent doses $(0.5 \mathrm{~g}, 1.0 \mathrm{~g}$ and $1.5 \mathrm{~g}$ in $100 \mathrm{~mL}$ ). There are many advantages of such factorial experimental designs, some of which require low cost, minimum numbers of experiments, reduced 
treatment time and the possibility to investigate the main and interaction effects separately (Nure et al. 2017).

\section{Materials and methods \\ Adsorbent development}

Catha edulis stem samples were collected from dumping sites of the large Addis Ababa Merkato market, which is locally called "Khat terra". The sample was washed with distilled water and dried in an oven at $100{ }^{\circ} \mathrm{C}$ until completely dried. The stems were cut into pieces at the size of $10 \mathrm{~mm}$. Carbonation and activation of C. edulis stem were performed using different activating agents, such as $\mathrm{KOH}, \mathrm{H}_{2} \mathrm{SO}_{4}$ and $\mathrm{H}_{3} \mathrm{PO}_{4}$ at temperatures of 500 and $600{ }^{\circ} \mathrm{C}$. Based on the prescreening, the activated carbon developed using $\mathrm{H}_{2} \mathrm{SO}_{4}$ at $600{ }^{\circ} \mathrm{C}$ was selected because it has a better fixed carbon composition and higher surface areas compared to the others. The procedure of the selected activating agent was started by soaking sample chips in concentrated $\mathrm{H}_{2} \mathrm{SO}_{4}$ for $24 \mathrm{~h}$ in order to achieve good carbon structure and a large surface area. The soaked sample was washed with distilled water and completely dried at $110{ }^{\circ} \mathrm{C}$ in an oven for $3 \mathrm{~h}$. Then, the pyrolysis of the sample was operated at a temperature of $600{ }^{\circ} \mathrm{C}$ for $60 \mathrm{~min}$ in a muffle furnace (Ali et al. 2012). The activated carbon was washed thoroughly with $3 \mathrm{~N} \mathrm{HCl}$ and heated to $50{ }^{\circ} \mathrm{C}$ to solubilize the mineral. Additionally, the activated carbon was washed with $1 \% \mathrm{NaHCO}_{3}$ to remove residual acid, and further washing was done using deionized water until $\mathrm{pH} 7$ of the activated carbon was achieved, which dried in an oven at $105^{\circ} \mathrm{C}$ for $12 \mathrm{~h}$ (Shivayogimath et al. 2008). Finally, the activated carbon was passed through a $0.5 \mathrm{~mm}$ sieve and sealed in a polyethylene bag which was stored for further characterization and uses as indicated in Fig. 1 (Gupta and Suhas 2009).

\section{Adsorbent characterization Proximate analysis}

In the determination of the proximate analysis of the $C$. edulis activated carbon (CAC), the moisture content, volatile matter, ash content and fixed carbon of the adsorbent were measured. The thermal drying method was applied for the proximate analysis of the adsorbent. The adsorbent sample of $1.0 \mathrm{~g}$ was weighed in triplicate and placed in a clean, dried, and weighed crucible in a preheated oven at $110{ }^{\circ} \mathrm{C}$. The crucibles with samples were placed in an oven at $110{ }^{\circ} \mathrm{C}$ for $2 \mathrm{~h}$. Then, the sample was cooled in desiccators at ambient temperature and its weight was measured again. Hence, the difference between the initial and the final mass of the CAC was used to determine the moisture content using Eq. 1.

$$
\mathrm{Mc}=\frac{\mathrm{W}_{\mathrm{w}}-\mathrm{W}_{\mathrm{d}}}{\mathrm{W}_{\mathrm{w}}} \times 100 \%
$$

where Mc is the moisture content of the CAC in percentage, $\mathrm{Ww}$ is the weight of the sample and $\mathrm{Wd}$ is the weight

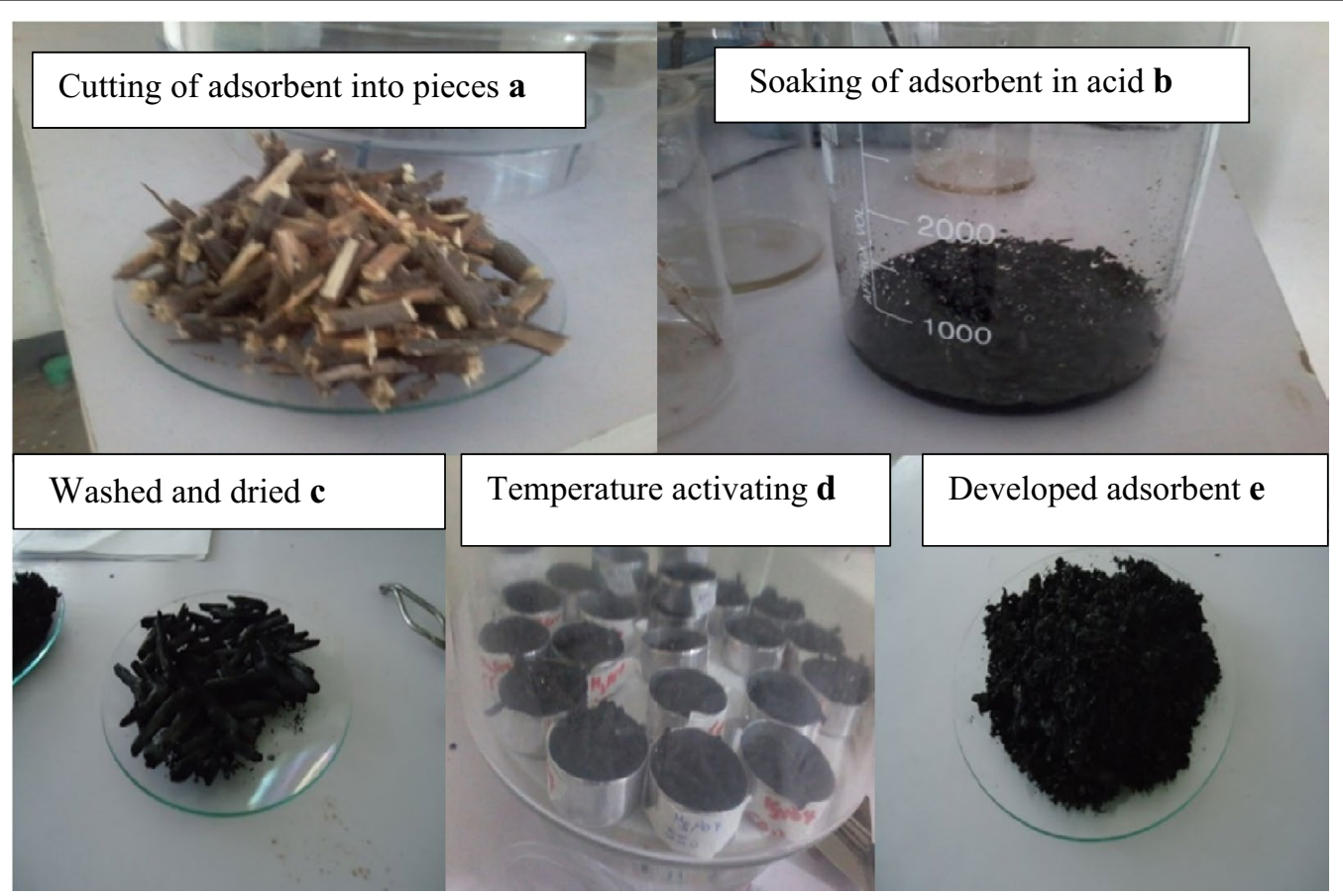

Fig. 1 Different stages of the activated carbon production 
of the sample after drying (Milne et al. 1990; Anisuzzaman et al. 2015)

Similarly, for the determination of the ash content of the CAC, $1.0 \mathrm{~g}$ of CAC sample was put into a crucible and heated at $500{ }^{\circ} \mathrm{C}$ in a muffle furnace for $4 \mathrm{~h}$ and allowed to cool in a desiccator to room temperature. Finally, the CAC sample was weighed and the percentage of the ash content of the CAC was calculated using Eq. 2 (Anisuzzaman et al. 2015).

$$
A C=\frac{W_{1}}{W_{2}} \times 100 \%
$$

where $\mathrm{AC}$ is the ash content in percentage, $\mathrm{W}_{2}$ is the weight of the CAC sample and $\mathrm{W}_{1}$ is the weight of the ash. For the determination of the volatile matter of the CAC, $1.0 \mathrm{~g}$ of the CAC sample was taken and placed in a pre-dried crucible and heated in a muffle furnace regulated at $800{ }^{\circ} \mathrm{C}$ for $8 \mathrm{~min}$. Then, the crucible was cooled in desiccators and weighed (Aragaw 2016). Finally, the volatile matter of the CAC was calculated using Eq. 3.

$$
V m=\frac{W_{2}-W_{1}}{W_{2}} \times 100 \%
$$

where $\mathrm{Vm}$ is the volatile matter in percentage, $\mathrm{W}_{2}$ is the weight of the CAC sample and $\mathrm{W}_{1}$ is the weight of CAC after heating. Fixed carbon content was determined by deducting the moisture, volatile, and ash content percentage using the Eq. 4 (Nwabanne and Igbokwe 2012).

$$
\text { Fixed Carbon Content }(\%)=100 \%-(\mathrm{MC} \%+\mathrm{VC} \%+\mathrm{Ash} \%)
$$

where the $\mathrm{MC} \%$ is moisture content in percent, $\mathrm{VC} \%$ is volatile content in percent, Ash\% is the ash content in percentage (Nure et al. 2017)

\section{Determination of $\mathrm{pH}$}

A $1.0 \mathrm{~g}$ of CAC was added to $100 \mathrm{~mL}$ of distilled water in a beaker of $500 \mathrm{~mL}$ volume in order to determine the $\mathrm{pH}$ value of CAC adsorbent. Then, the beaker was covered with a watch glass and boiled on the hot plate for $5 \mathrm{~min}$ and set aside for a few minutes to settle the bulk of CAC particles. The supernatant liquid was poured off and cooled to the room temperature at a $25{ }^{\circ} \mathrm{C}$. Finally, the $\mathrm{pH}$ value of the solution was measured by using a $\mathrm{pH}$ meter (Hach HQD Field Case Model 58258-00) (Dada et al. 2012)

\section{Bulk density}

The mass to volume ratio of CAC adsorbent was used to determine the bulk density. A measuring cylinder of a volume of $10 \mathrm{~cm}^{3}$ was weighted without and with the adsorbent sample. The difference between the initial weight of the container and the final weight was calculated. This mass difference was taken as the mass of the CAC adsorbent. Then, the bulk density was calculated from the relationship of mass to volume and determined using Eq. 5,

$$
\operatorname{Bulk} \text { Density }\left(\mathrm{kg} / \mathrm{m}^{3}\right)=\frac{\mathrm{M}}{\mathrm{V}}
$$

where $M$ is the mass of a sample $(\mathrm{kg})$, whereas the $\mathrm{V}$ is the volume of the adsorbent sample $\left(\mathrm{m}^{3}\right)$ (Dada et al. 2012)

\section{Fourier transform infrared spectroscopy}

$\mathrm{CAC}$ was characterized using Fourier transform infrared spectroscopy (FTIR). The CAC adsorbent was mixed with dry $\mathrm{KBr}$ in the ratio of 2:200 in $\mathrm{mg}$ and ground very well. The adsorbent sample was scanned over a wavelength of $400-4000 \mathrm{~cm}^{-1}$ using FTIR spectrophotometry (65 FT-IR PerkinElmer) (Dolphen and Thiravetyan 2011). This was designed to determine the availability of the functional groups on the surface of CAC.

\section{Optimization of batch adsorption}

In order to prepare a fluoride solution of $1000 \mathrm{mg} / \mathrm{L}$, $2.21 \mathrm{~g}$ of $\mathrm{NaF}$, salt was dissolved in $1 \mathrm{~L}$ of deionized water and the standard solution $(30 \mathrm{mg} / \mathrm{L})$ was prepared by diluting the stock solution with deionized water. The adsorption batch experiment was carried out using $100 \mathrm{~mL}$ of adsorbate solution into $250 \mathrm{~mL}$ conical flasks. This adsorption process was investigated using initial fluoride concentration $30 \mathrm{mg} / \mathrm{L}$ based on the maximum fluoride concentration in many places in Ethiopia, particularly in the Rift Valley. The fixed values of independent values were $\mathrm{pH}(2,7$ and 9), contact times $(60,90$ and $120 \mathrm{~min})$ and CAC doses $(0.5 \mathrm{~g}, 1.0 \mathrm{~g}$ and $1.5 \mathrm{~g}$ in $100 \mathrm{~mL}$ ) were selected (Tezcan et al. 2015). The design of this experiment was a $3^{3}$ full factorial design with 81 runs with triplicates at room temperature (Table 1). The $\mathrm{pH}$ of the solutions was adjusted using $0.1 \mathrm{~N}$ of $\mathrm{HNO}_{3}$ and $\mathrm{NaOH}$ solutions. The flasks were agitated at $120 \mathrm{rpm}$

Table 1 Factors and their levels for removal of fluoride using full factorial design

\begin{tabular}{lllll}
\hline Factors & Code & $\begin{array}{l}\text { Minimum } \\
\text { level }\end{array}$ & $\begin{array}{l}\text { Intermediate } \\
\text { level }\end{array}$ & Maximum level \\
\hline $\begin{array}{l}\text { Dosage } \\
(\mathrm{g} / 100 \mathrm{~mL})\end{array}$ & $\mathrm{X}_{1}$ & 0.5 & 1 & 1.5 \\
$\mathrm{pH}$ & $\mathrm{X}_{2}$ & 2 & 7 & 9 \\
$\begin{array}{c}\text { Contact time } \\
(\text { min. })\end{array}$ & $\mathrm{X}_{3}$ & 60 & 90 & 120 \\
\hline
\end{tabular}


using magnetic stirrers on an orbital shaker for specified contact times labeled. Then, the solution was left to settle for $2 \mathrm{~min}$ and the finer particles were removed using Whitman filter paper 42 (Hegazy et al. 2014; Nure et al. 2017). The filtrate sample was used for the analysis of fluoride removal. Finally, the reading of the electrode was made after the value stabilized for $15 \mathrm{~min}$.

\section{Adsorption equilibrium isotherms}

The adsorption isotherm was determined by using adsorbent doses of $0.5,1.0,1.5,2.0,2.5,3.0,3.5$ and $4.0 \mathrm{~g}$ which were added in $100 \mathrm{~mL}$ of the fluoride solution $(30 \mathrm{mg} / \mathrm{L})$ at constant values of $\mathrm{pH} 2$ and contact time of $60 \mathrm{~min}$. Equilibrium adsorption capacity $\left(\mathrm{q}_{\mathrm{e}}, \mathrm{mg} / \mathrm{g}\right)$ is the ratio of the adsorbate per amount of the adsorbent at the equilibrium concentration $\left(C_{\mathrm{e}}\right)$, keeping the operational temperature constant (room temperature). This adsorption equilibrium is checked using the two commonly used Freundlich and Langmuir isotherm models (Nure et al. 2017). The amount of the adsorptive capacity was calculated using Eq. 6.

$$
\mathrm{q}_{\mathrm{e}}=\left(\frac{\mathrm{C}_{0}-\mathrm{C}_{\mathrm{e}}}{\mathrm{m}}\right) \mathrm{V}
$$

General Langmuir isotherm equation was indicated in Eq. 7.

$$
q_{e}=\frac{Q_{O} C_{e} b}{1+C_{e} b}
$$

where $\mathrm{Ce}$ equilibrium is the concentration $(\mathrm{mg} / \mathrm{L}), Q_{o}$ maximum adsorption capacity $(\mathrm{mg} / \mathrm{g}), q_{e}$ absorptivity capacity $(\mathrm{mg} / \mathrm{g})$, and $b$ Langmuir isotherm constant (L/ $\mathrm{mg}$ ) (Tezcan et al. 2015).

The Freundlich isothermal model is expressed in Eq. (8).

$$
q=K_{f} C \mathrm{e}^{1 / n}
$$

where the $\mathrm{q}(\mathrm{mg} / \mathrm{g})$ is the adsorbed amount of the adsorbate per unit mass of the adsorbent, $\mathrm{Ce}(\mathrm{mg} / \mathrm{L})$ is the equilibrium concentration in $\mathrm{mg} / \mathrm{L}, \mathrm{K}_{\mathrm{f}}((\mathrm{mg} / \mathrm{g})(\mathrm{L} / \mathrm{mg}) 1 / \mathrm{n})$ and $1 / \mathrm{n}$ are the Freundlich constants which represent adsorption capacity and adsorption intensity, respectively (Nure et al. 2017).

\section{Statistical analysis}

One-way analysis of variance (ANOVA) was used for means comparison of fluoride removal at the $95 \%$ confidence level. The removal of the fluoride through the treatment of the adsorption was also further supported by linear regression among the independent variables $(\mathrm{pH}$, contact time and adsorbent dose $)$ and dependent variable (removal efficiency).

\section{Results and discussion}

\section{Characterization of activated carbon}

The proximate analysis of the $\mathrm{CAC}$ with $\mathrm{H}_{2} \mathrm{SO}_{4}$ was analyzed and the results obtained were displayed in Table 2 . Basically, the intention of the experiment was to determine the composition of fixed carbon and ash content. The high composition of the fixed carbon refers to the quality of the adsorbent which improves the surface area and adsorption performance. A very low value of the CAC moisture content of $4 \%$ was recorded, which is an indicator of its good quality. The volatile matter of the adsorbent was $25 \%$, whereas the ash content was only $18 \%$, which proved that the inorganic content was insignificant. In other studies of activated carbon derived from holm oak, high percentage of ash content of $70.6 \%$ was reported, which was much higher than that of activated carbon produced from C. edulis (Tezcan et al. 2015). The high content of ash can be explained as low quality of the raw material behavior for adsorbent preparation. This happened because the large amount of ash content is not favorable for activated carbon development and resulted in low carbon content, which in turn can lower the adsorption capacity and efficiency. Hence, adsorbent development with low ash content is one of the critical concerns of scientists and researchers working on water and wastewater purification processes through adsorption treatment technology.

Another most important parameter was fixed carbon, which was $53 \%$, a significant amount for local prepared activated carbon. In another study of locally developed activated carbon, a moisture content of $4.0 \%$, ash $36.0 \%$, fixed carbon $42.2 \%$ and volatile substances of $16.8 \%$ were reported, which is in good agreement with the current study (Nure et al. 2017). Generally, the prepared activated carbon was a more carbonaceous material and a good precursor for adsorbent development, which contributed to water and wastewater purification at the industrial level.

The bulk density of CAC developed using $\mathrm{H}_{2} \mathrm{SO}_{4}$ and high temperature of $600{ }^{\circ} \mathrm{C}$ at the specific particle size of nearly $0.5 \mathrm{~mm}$ was determined. On average, a bulk density of $0.46 \mathrm{~g} / \mathrm{cm}^{3}$ was obtained. This value was found in the acceptable range of the carbonaceous materials

Table 2 Proximate analyses of CAC adsorbent after treatment with sulfuric acid

\begin{tabular}{lc}
\hline Proximate analysis & Mass in \% \\
\hline Moisture & 4.0 \\
Volatile matter & 25.0 \\
Ash content & 18.0 \\
Fixed carbon $^{\mathrm{a}}$ & 53.0 \\
\hline
\end{tabular}

a The result was calculated by difference 
Table 3 FTIR analyses, AC peak observed and corresponding functional groups

\begin{tabular}{lllll}
\hline SN & Wave length in $\mathbf{~ c m}^{\mathbf{- 1}}$ & Peaks nature of AC & Functional groups \\
\cline { 3 - 4 } & Before & After treatment & \\
\hline 1 & $3300-3600$ & Small sharp peak & Diminished small sharp peak & Presence of O-H \\
2 & 2944 & Small sharp peak & Small sharp peak & Stretching C-H \\
3 & $1500-1600$ & Long and broad peak & Diminished small peak & Carboxylate bond \\
4 & 1425 & Small peak & Very small peak & C-C stretched (aromatic) \\
5 & 800 & Sharp peak & No peak & C=CH stretched \\
\hline
\end{tabular}

of 0.35 to $1.2 \mathrm{~g} / \mathrm{m}^{3}$ as reported by many studies (Sunday et al. 2018). Normally, high bulk density is considered to be a good quality of the adsorbent materials. Hence, the CAC showed good material characteristics in terms of the bulk density value found in the recommendable range of the ideal adsorbent. Finally, the $\mathrm{pH}$ value of $\mathrm{CAC}$ that activated by sulfuric acid was found to be nearly neutral.

In an FTIR analysis of the $C$. edulis, three major peaks were observed and shown in Table 3. The first peak was found in the range of the wavelength $3300-3600 \mathrm{~cm}^{-1}$ indicates the presence of the hydroxyl functional group which could be associated to the organic acid, alcohol, or phenol functional group. The second group was found in the range of the $1500-1600 \mathrm{~cm}^{-1}$ wavelength related to the stretching of the carboxylate bond. These two broad and long peaks observed on the surface of the adsorbent were probably associated with the chemical activation process of the adsorbent. This particular surface modification might be attributed to hydrogen ion released from sulfuric acid and could be resulted in the development of the hydroxide functional group on the surface of the adsorbent. The last weak peak was found at the wavelength of $1425 \mathrm{~cm}^{-1}$ which was most likely associated with the functional group of the $\mathrm{C}-\mathrm{C}$ stretching of the aromatic compound.

\section{Fluoride removal analyses}

The results of the fluoride removal from aqueous solution using experimental design of the factorial matrix and the corresponding predicted values are shown in Table 4 The adsorption efficiency was increased by $16 \%$ as the adsorbent dose shifted from low value $(0.5 \mathrm{~g})$ to a high value $(1.5 \mathrm{~g}$ in $100 \mathrm{~mL})$, but the efficiency was decreased by the same value as the $\mathrm{pH}$ of the solution shifted from 2 to 9, keeping other factors constant. However, the effect of raising the contact time from 60 to $120 \mathrm{~min}$ on the adsorption performance was insignificant. This indicated that the adsorption equilibrium was achieved at the lower contact time of the adsorption process. The overall effect of the independent factors on adsorption performance was investigated using the full factorial approach. The results obtained were considered both the main and
Table 4 Full factorial experimental matrix for fluoride removal displayed in percentage

\begin{tabular}{|c|c|c|c|c|c|}
\hline Experiment \# & $\begin{array}{l}\text { Dose } \\
(\mathrm{mg} / 100 \mathrm{~L})\end{array}$ & $\mathrm{pH}$ & Time & Actual \% & Predicted $\%$ \\
\hline 1 & 0.5 & 2 & 60 & 56.7 & 60.0 \\
\hline 2 & 1 & 2 & 60 & 68.0 & 63.4 \\
\hline 3 & 1.5 & 2 & 60 & 73.0 & 66.8 \\
\hline 4 & 0.5 & 7 & 60 & 45.3 & 48.8 \\
\hline 5 & 1 & 7 & 60 & 50.0 & 52.3 \\
\hline 6 & 1.5 & 7 & 60 & 51.7 & 55.7 \\
\hline 7 & 0.5 & 9 & 60 & 40.7 & 42.6 \\
\hline 8 & 1 & 9 & 60 & 49.3 & 46.1 \\
\hline 9 & 1.5 & 9 & 60 & 49.7 & 49.5 \\
\hline 10 & 0.5 & 2 & 90 & 61.7 & 58.5 \\
\hline 11 & 1 & 2 & 90 & 65.0 & 61.9 \\
\hline 12 & 1.5 & 2 & 90 & 66.7 & 65.4 \\
\hline 13 & 0.5 & 7 & 90 & 46.7 & 47.3 \\
\hline 14 & 1 & 7 & 90 & 46.0 & 50.8 \\
\hline 15 & 1.5 & 7 & 90 & 49.7 & 54.2 \\
\hline 16 & 0.5 & 9 & 90 & 46.3 & 41.2 \\
\hline 17 & 1 & 9 & 90 & 43.3 & 44.6 \\
\hline 18 & 1.5 & 9 & 90 & 49.0 & 48.0 \\
\hline 19 & 0.5 & 2 & 120 & 57.0 & 57.0 \\
\hline 20 & 1 & 2 & 120 & 64.0 & 60.5 \\
\hline 21 & 1.5 & 2 & 120 & 63.0 & 63.9 \\
\hline 22 & 0.5 & 7 & 120 & 43.7 & 45.6 \\
\hline 23 & 1 & 7 & 120 & 47.0 & 49.3 \\
\hline 24 & 1.5 & 7 & 120 & 50.0 & 52.7 \\
\hline 25 & 0.5 & 9 & 120 & 40.3 & 39.7 \\
\hline 26 & 1 & 9 & 120 & 45.7 & 43.1 \\
\hline 27 & 1.5 & 9 & 120 & 49.7 & 46.5 \\
\hline
\end{tabular}

interaction effects, which represented the reality. Based on this fact, the maximum fluoride removal of $73 \%$ was observed at the optimum condition of adsorbent dose of $1.5 \mathrm{~g}$ in $100 \mathrm{~mL}$, contact time of $60 \mathrm{~min}$ and $\mathrm{pH} 2$ at the fixed and initial fluoride concentration operated at room temperature; the predicted value of $69 \%$ was calculated under the same experimental condition. Through all the 
adsorption experiments, the minimum adsorption of $40.7 \%$ was recorded at an adsorbent dose of $0.5 \mathrm{~g}$, contact time $60 \mathrm{~min}$ and the $\mathrm{pH}$ of the adsorption solution was 9. In other studies, fluoride removal in the range of $50-99 \%$ at an initial fluoride concentration of $1-12 \mathrm{mg} / \mathrm{L}$ with the help of the barks of Vitex negundo activated carbon (Suneetha et al. 2015); 76\% fluoride removal at an initial concentration of $25 \mathrm{mg} / \mathrm{L}$ using lapsi seed stone activated carbon (Sahira et al. 2013); adsorption capacity of $26 \mathrm{mg} / \mathrm{g}$ through the application of the bark of Morinda tinctoria as an adsorbent (Amalraj and Pius 2017); fluoride removal of $85 \%$ at initial solution $6.5 \mathrm{mg} / \mathrm{L}$ with the crocus sativus leaves adsorbent (Dehghani et al. 2018); and fluoride removal efficiency of $81 \%$ at an initial concentration of 1-5 mg/L with the modified sludge adsorbent (Li et al. 2018) were reported.

\section{The main and interaction effects on adsorption}

In this regression analysis, terms of the higher interaction effects such as three and four ways had no significant impact on adsorption performance. These terms were excluded from the regression analyses and from the model equation. The impacts of the main and two way interaction on the adsorption were investigated at 95\% confidence level (Table 5). Basically, there are two important concepts in linear regression models, namely: the regression coefficient of determination $\left(R^{2}\right)$, which is used to describe the degree of the variability explained by the regression model, and the $p$ value which helps to check whether the main and interaction effects are statistically significant in the performance of adsorption.
Based on this principle, there were only two main effects, which were used to determine the influence on the adsorption treatment. Accordingly, only coefficient $b_{1}$ and $b_{2}$ were statically significant in this adsorption process and incorporated in the model Eq. (9). The $R^{2}$ value of the fluoride removal from aqueous solution was $92 \%$, which was considered as $92 \%$ of fluoride removal was well explained by the liner regression model. This was a good indicator for the regression model goodness of fit. These statistically significant terms and their values were incorporated in the regression Eq. (9).

$$
Y_{\text {flouride }}=64.70+12.21 X_{1}-3.4 X_{2}
$$

where $\mathrm{Y}_{\text {fluoride }}$ was the predicted value of the fluoride removal in percentage; $X_{1}$ was adsorbent dose and $X_{2}$ was $\mathrm{pH}$ of the solution; the other main and interaction effects were not significant and removed from this equation. The regression coefficient of adsorbent dose was positive and enhanced the adsorption performance but increasing the $\mathrm{pH}$ value of the solution suppressed the adsorption performance as depicted by the negative coefficient in the model equation. The degree of impact on the adsorption process was $X_{1} \gg X_{2}$, which basically depended on the magnitudes and the signs of the coefficients in the model equation. Generally, the adsorption performance was highly and positively influenced by the adsorbent dose but weakly and negatively influenced by the $\mathrm{pH}$ of the solution. Finally, the one-way ANOVA test showed that there were statistically significant differences among mean fluoride concentrations of the adsorption effluent after the treatment.

Table 5 The application of regression and ANOVA tests for fluoride removal

\begin{tabular}{llllll}
\hline Variables & Coefficients symbol & Coefficients & Standard error & t Stat & p-value \\
\hline Intercept & b0 & 64.70 & 7.32 & 8.83 & $3.73 \mathrm{E}-08$ \\
X1 & b1 & 12.21 & 5.40 & 2.26 & 0.036 \\
X2 & b2 & -3.37 & 0.75 & -4.49 & 0.000 \\
X3 & b3 & -0.05 & 0.08 & -0.56 & 0.580 \\
X1X2 & b4 & -0.03 & 0.20 & -0.13 & 0.897 \\
X1X3 & b5 & -0.04 & 0.07 & -0.67 & 0.513 \\
X2X3 & b6 & 0.01 & 0.01 & 0.02 & 0.319 \\
X1X2X3 & b7 & -0.02 & 0.01 & -0.38 & Observations \\
\hline Regression statistics & Multiple R & R square & Adjusted R square & Standard error & 27 \\
\hline & 0.96 & 0.92 & 0.89 & 2.99 & Significance F \\
\hline ANOVA & df & SS & MS & 31.49 & $3.71 \mathrm{E}-09$ \\
\hline Regression & 7 & 1965.85 & 280.84 & & \\
Residual & 19 & 169.43 & & & \\
Total & 26 & 2135.28 & & & \\
\hline
\end{tabular}




\section{Adsorption isotherms}

The adsorption isotherm data were collected from adsorption capacity $\left(\mathrm{q}_{\mathrm{e}}\right)$ and the equilibrium concentration of the fluoride $\left(\mathrm{C}_{\mathrm{e}}\right)$. But the adsorption isotherms were investigated using the most commonly used adsorption models, namely Langmuir and Freundlich isotherms. The linearized form of the Langmuir Eq. 10 was used.

$$
\frac{1}{q_{e}}=\frac{1}{Q_{O}}+\frac{1}{Q_{o} b C_{e}}
$$

Langmuir adsorption isotherm is based on the assumption that the adsorbent surface sites are capable of adsorbing one adsorbate at a time so that the layer of the adsorbent would have a mono layer thickness. Once the adsorbate matters occupy the sites, no further adsorption is expected. Langmuir isotherm was determined by plotting $\left(1 / \mathrm{q}_{\mathrm{e}}\right)$ versus $\left(1 / \mathrm{C}_{\mathrm{e}}\right)$, as indicated in Fig. 2 . Based on this plot, the maximum adsorption capacity $\left(\mathrm{Q}_{\mathrm{o}}\right)$ and Langmuir isotherm constant (b) were calculated from the intercept and slope of the Langmuir equation, respectively.

Langmuir isothermal adsorption constant (b) was found to be $0.05 \mathrm{~L} / \mathrm{mg}$ and related to the free energy of adsorption, whereas the maximum adsorption capacity $\left(\mathrm{Q}_{\mathrm{o}}\right)$ was $18 \mathrm{mg} / \mathrm{g}$. Even though the highest value of the $\mathrm{R}^{2}(0.96)$ indicated a satisfactory fit of the Langmuir isotherm with the experimental data, the maximum adsorption capacity deviated much from the observed data (33 mg/g). Therefore, the model couldn't well describe the mechanism of the adsorption process under the study condition. Based on the outcome of the Langmuir isotherm, it is difficult to make a decision on the prediction and improvement of the adsorbing surface chemistry. Therefore, the assumption of mono layer mechanism of the adsorption process has not well defined the phenomena, indicating the need to check it using other assumptions. However, the dimensionless constant parameter called separation constant $\left(\mathrm{R}_{\mathrm{L}}\right)$ of the Langmuir adsorption process was also checked. The effect of the adsorption isothermal shape was determined by the value of the

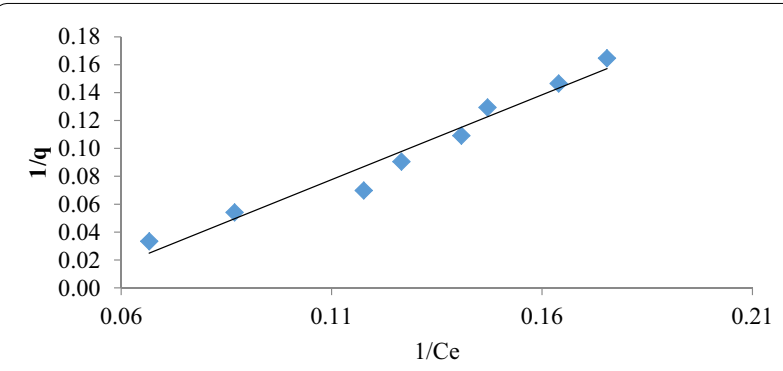

Fig. 2 Langmuir isotherm plot for fluoride removal using CAC
$\mathrm{R}_{\mathrm{L}}$ to identify whether the adsorption system was favorable or unfavorable. Basically, this value can be calculated using Eq. 11,

$$
R_{\mathrm{L}}=\frac{1}{1+b C_{\mathrm{o}}}
$$

where $R_{\mathrm{L}}$ is a dimensionless separation factor, $C_{\mathrm{O}}$ the initial fluoride concentration $(\mathrm{mg} / \mathrm{L})$ and $b$ the Langmuir constant $(\mathrm{L} / \mathrm{mg})$. The parameter $R_{\mathrm{L}}$ indicates the shape of the isotherm, which reflects when $R_{L}>1$ (unfavorable); $\mathrm{R}_{\mathrm{L}}=1$ (linear); $0<\mathrm{R}_{\mathrm{L}}<1$ (favorable) and when $\mathrm{R}_{\mathrm{L}}=0$ is irreversible. Based on the above equation, the calculated value of $R_{L}$ was 0.4 . This value suggested that the adsorption process was categorized under the favorable adsorption group.

\section{Freundlich isotherm}

Similar to the Langmuir isotherm, the experimental data were checked against a linearized form of the Freundlich isotherm Eq. 12. The Freundlich isothermal plot of the linear equation is shown in Fig. 3. The adsorption isotherm is described by the relationship between the bulk aqueous concentration of fluoride and the adsorbed value on the surface of the adsorbent.

$$
\log q=\log K_{f}+\frac{1}{n} \log C e
$$

Freundlich isotherm is based on the assumption of heterogeneous surface composing of the different sites for adsorption. It doesn't forecast the adsorbent saturation level of the adsorbate which implies that the multilayer of adsorption phenomena is expected under such condition. Freundlich isotherm graph was sketched using $\log \mathrm{q}_{\mathrm{e}} \mathrm{vs}$ $\log C_{e}$. The values of $K_{f}$ and $n$ were obtained from the intercept and slope of the linearized form of Freundlich equation, respectively. Specifically, $\mathrm{n}$ is the degree of nonlinearly between solution concentration and adsorption

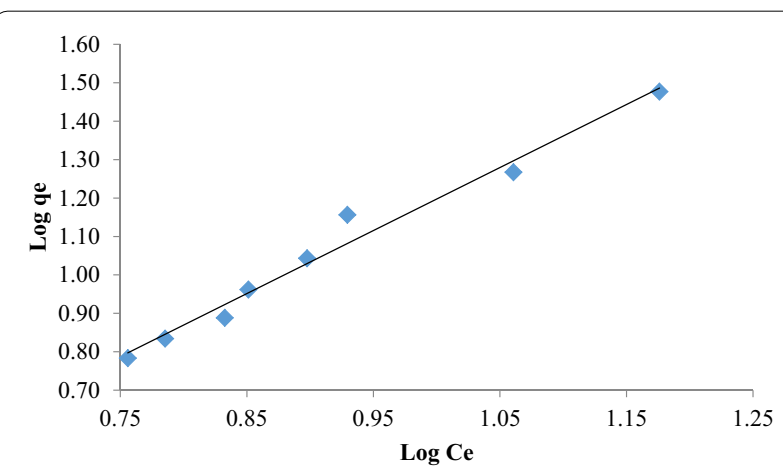

Fig. 3 Freundlich isotherm plot for fluoride removal from aqueous solution using CAC 
capacity in addition to its relationship with the favorability of the adsorption process, whereas the $\mathrm{K}_{\mathrm{f}}((\mathrm{mg} / \mathrm{g})(\mathrm{L} /$ $\mathrm{mg})^{1 / \mathrm{n}}$ ) is an indicator of adsorption capacity.

Based on the Freundlich isotherm, Freundlich intensity (n) of 0.61 and the adsorption capacity $\left(\mathrm{K}_{\mathrm{f}}\right)$ of 0.094 were calculated, which basically depend on the nature of the adsorbate and the temperature of the system. The value of $n=1$ indicates that the equilibrium distribution between the solid and liquid phase is independent of the concentration, whereas the values of $1 / n>1$ or $1 / n<1$ show cooperative and normal adsorption, respectively (Nure et al. 2017). Moreover, the degree of the surface heterogeneity increases sharply as the value of $1 / n$ decreases (Liu et al. 2015). Specifically, the Freundlich intensity (n) value indicated that the adsorption process was a cooperative, which was reported in several recently published journal articles (Nure et al. 2017). Generally, the Freundlich isotherm depicted that the adsorption process was heterogeneous and had multilayer surfaces, suggesting that the binding sites were not equivalent but with different adsorption layers. From the Freundlich equation, $R^{2}$ of 0.98 was found and could be considered as good fitness of the model to describe the adsorption mechanism. But the Langmuir maximum adsorption capacity showed a weak association between the calculated and the observed adsorption capacity, which was also further supported by its low value of $R^{2}$ compared to the Freundlich isotherm.

\section{Conclusions}

This study investigated the removal fluoride ions from aqueous solution using chemically (sulfuric acid) activated $C$. edulis stems under the batch adsorption mode. Four factors such as the adsorbent dose, contact time and $\mathrm{pH}$ of solution were used in factorial experimental design under adsorption study. The maximum fluoride removal of $73 \%$ was recorded at the optimum condition of adsorbent dose of $1.5 \mathrm{~g}$ in $100 \mathrm{~mL}$, contact time $60 \mathrm{~min}$ and $\mathrm{pH} 2$, whereas the model based predicted value of the fluoride removal under the same experimental condition was $69 \%$. Fluoride removal was positive and strongly influenced by the adsorbent dose whereas the adsorption $\mathrm{pH}$ was negatively and weakly impacted on the removal. Removal of fluoride was effectively achieved using chemically modified of $C$. edulis. These results showed significant fluoride removal under the specific study condition. Experiment-based maximum adsorptive capacity was found to be $33.3 \mathrm{mg} / \mathrm{g}$, whereas the predicted value under Langmuir isotherm study was $18 \mathrm{mg} / \mathrm{g}$. Catha edulis was found to be a good precursor for activated carbon and have a good adsorption capacity. Freundlich isotherm $\left(\mathrm{R}^{2}\right.$ 0.98) was better fitted to the experimental data, which indicated that the adsorption process was multilayer and cooperative. Generally, the performance of activated carbon for the removal of fluoride from aqueous solution is a promising which would make the CAC a potential nominee to be used in water treatment technology. However, further study of the treatment technology is expected in respect to the adsorbent recovery, adsorption kinetics and thermodynamics.

\section{Abbreviations \\ ANOVA: analysis of variance; CAC: Catha edulis activated carbon; FTIR: Fourier transform infrared spectroscopy; UN: United Nations; WHO: World health organization.}

\section{Acknowledgements}

We would like to thank the Ethiopian Road Authority for funding this research work and Addis Ababa Science and Technology University for supervising the financial support given by the authority.

\section{Authors' contributions}

JF contributed for experimental design, experimental supervision, statistical analysis, and manuscript writing and editing whereas HS, SF and AW mainly contributed for data collection and manuscript editing. All authors read and approved the final manuscript.

\section{Funding}

This research work was supported by Ethiopian Road Authority

\section{Availability of data and materials}

The details information how and where the data collection done was described in body the manuscript.

\section{Ethics approval and consent to participate}

This part is not applicable for this article.

\section{Consent for publication}

This part is not applicable for this article.

\section{Competing interests}

We authors have read and understood the policy of the competing interests and declare that there is no competing interests among the authors and the fund provider for this work.

\section{Author details}

${ }^{1}$ Department of Environmental Engineering, Addis Ababa Science and Technology, P.O.Box 16417, Addis Ababa, Ethiopia. ${ }^{2}$ Water and Energy Design and Supervision Works Sector, Ethiopian Construction Design and Supervision Works Corporation, Addis Ababa, Ethiopia. ${ }^{3}$ Ethiopian Agriculture Research Council Secretariat, P.O.Box 8115, Addis Ababa, Ethiopia.

Received: 9 March 2019 Accepted: 17 June 2019

Published online: 30 June 2019

\section{References}

Ali I, Asim M, Khan TA (2012) Low cost adsorbents for the removal of organic pollutants from wastewater. J Environ Manage 113:170-183. https://doi. org/10.1016/j.jenvman.2012.08.028

Amalraj A, Pius A (2017) Removal of fluoride from drinking water using aluminum hydroxide coated activated carbon prepared from bark of Morinda tinctoria. Appl Water Sci 7:2653-2665. https://doi.org/10.1007/ s13201-016-0479-z

Anisuzzaman SM, Joseph CG, Taufiq-Yap YH et al (2015) Modification of commercial activated carbon for the removal of 2,4-dichlorophenol from simulated wastewater. J King Saud Univ Sci 27:318-330. https://doi. org/10.1016/j.jksus.2015.01.002 
Aragaw TA (2016) Proximate analysis of cane bagasse and synthesizing activated carbon: emphasis on material balance. J Environ Treat Tech 4:102-110

Asaithambi P, Beyene D, Raman A et al (2018) Removal of pollutants with determination of power consumption from landfill leachate wastewater using an electrocoagulation process: optimization using response surface methodology (RSM). Appl Water Sci 8:1-12. https://doi.org/10.1007/ s13201-018-0715-9

Bhattacharya S (2017) Application of nanostructured materials in fluoride removal from contaminated groundwater. Eur Water 58:87-93

Dada AO, Olalekan AP, Olatunya AM, Dada O (2012) Langmuir, Freundlich, Temkin and Dubinin—Radushkevich isotherms studies of equilibrium sorption of Zn 2+ unto phosphoric acid modified rice husk. IOSR J Appl Chem 3:38-45. https://doi.org/10.9790/5736-0313845

Dehghani MH, Farhang M, Afsharnia M, Mckay G (2018) Adsorptive removal of fluoride from water by activated carbon derived from $\mathrm{CaCl}_{2}-$ modified Crocus sativus leaves : equilibrium adsorption isotherms, optimization, and influence of anions. Chem Eng Commun. https://doi. org/10.1080/00986445.2018.1423969

Dolphen R, Thiravetyan P (2011) Adsorption of melanoidins by chitin nanofibers. Chem Eng J 166:890-895

Fito J, Alemu K (2019) Microalgae-bacteria consortium treatment technology for municipal wastewater management. Nanotechnol Environ Eng 4:1-9. https://doi.org/10.1007/s41204-018-0050-2

Fito J, Tefera N, Demeku S, Kloos H (2017a) Water footprint as an emerging environmental tool for assessing Sustainable water use of the bioethanol distillery at Metahara sugarcane farm, Oromiya Region, Ethiopia. Water Conserv Sci Eng 2:165-176. https://doi.org/10.1007/s41101-017-0038-y

Fito J, Tefera N, Van Hulle SWH (2017b) Adsorption of distillery spent wash on activated bagasse fly ash: kinetics and thermodynamics. J Environ Chem Eng 5:5381-5388. https://doi.org/10.1016/j.jece.2017.10.009

Fito J, Bultossa G, Kloos H (2019a) Physicochemical and heavy metal constituents of the groundwater quality in Haramaya Woreda, Oromia Regional State, Ethiopia. Int J Energy Water Resour 3:23-32. https://doi. org/10.1007/s42108-019-00009-9

Fito J, Tefera N, Van Hulle SWH (2019b) Physicochemical properties of the sugar industry and ethanol distillery wastewater and their impact on the environment. Sugar Tech 21:265-277. https://doi.org/10.1007/s1235 5-018-0633-z

Fito J, Tefera N, Van Hulle WH (2019c) An integrated treatment technology for blended wastewater of the sugar industry and ethanol distillery. Environ Process. https://doi.org/10.1007/s40710-019-00366-x

Gupta VK, Suhas (2009) Application of low-cost adsorbents for dye removal-a review. J Environ Manage 90:2313-2342. https://doi.org/10.1016/j.jenvm an.2008.11.017

Hegazy AK, Abdel-Ghani NT, El-Chaghaby GA (2014) Adsorption of phenol onto activated carbon from seaweed: determination of the optimal experimental parameters using factorial design. Appl Water Sci 42:952956. https://doi.org/10.1016/j.jtice.2011.04.003

Jagtap S, Yenkie MK, Labhsetwar N, Rayalu S (2012) Fluoride in drinking water and defluoridation of water. Chem Rev 112:2454-2466

Joshi S, Pradhananga MA, Pradhananga RR (2012) Adsorption of fluoride ion onto zirconyl_-impregnated activated carbon prepared from lapsi seed stone. J Nepal Chem Soc 30:13-23

Kebede B, Beyene A, Fufa F (2016) Experimental evaluation of sorptive removal of fluoride from drinking water using iron ore. Appl Water Sci 6:57-65. https://doi.org/10.1007/s13201-014-0210-x

Kofa GP, Gomdje VH, Telegang C, Koungou SN (2017) Removal of fluoride from water by adsorption onto fired clay pots: kinetics and equilibrium studies. J Appl Chem 2017:1-7. https://doi.org/10.1155/2017/6254683

Lavecchia R, Medici F, Piga L, Rinaldi G (2012) Fluoride removal from water by adsorption on a high alumina content bauxite. Chem Eng Trans 26:225-230

Li Y, Yang S, Jiang Q et al (2018) The adsorptive removal of fluoride from aqueous solution by modified sludge: optimization using response surface methodology. Int J Environ Res Public Health 15:1-14. https://doi. org/10.3390/ijerph15040826

Liu H, Deng S, Li Z et al (2010) Preparation of Al-Ce hybrid adsorbent and its application for defluoridation of drinking water. J Hazard Mater 179:424-430. https://doi.org/10.1016/j.jhazmat.2010.03.021
Liu G, Xiao J, Ren H, Zhong H (2015) Adsorption thermodynamics and kinetics of N, N'-diisopropoxypropyl-N"', N"'-oxydiethylenedicarbonyl bis (thiourea) on chalcopyrite surfaces. J Ind Eng Chem 21:1306-1313. https://doi. org/10.1016/j.jiec.2014.06.003

Loganathan P, Vigneswaran S, Kandasamy J, Naidu R (2013) Defluoridation of drinking water using adsorption processes. J Hazard Mater 248-249:1-19. https://doi.org/10.1016/j.jhazmat.2012.12.043

Milne T, Brennan A, Glenn B (1990) Sourcebook of methods of analysis for biomass conversion and biomass conversion processes. Elsevier, London

Mohapatra M, Anand S, Mishra BK et al (2009) Review of fluoride removal from drinking water. J Environ Manage 91:67-77. https://doi.org/10.1016/j. jenvman.2009.08.015

Mulugeta E, Zewge F, Johnson CA, Chandravanshi BS (2015) Aluminium hydro (oxide)- based $(\mathrm{AO})$ adsorbent for defluoridation of drinking water: optimisation, performance comparison, and field testing. Water SA 41:121-128

Nienie AB, Sivalingam P, Laffite A et al (2017) Seasonal variability of water quality by physicochemical indexes and traceable metals in suburban area in Kikwit, Democratic Republic of the Congo. Int Soil Water Conserv Res 5:158-165. https://doi.org/10.1016/j.iswcr.2017.04.004

Nigussie W, Zewge F, Chandravanshi BS (2007) Removal of excess fluoride from water using residue from alum Removal of excess fluoride from water using waste residue from alum manufacturing process. J Hazard Mater 147:954-963. https://doi.org/10.1016/j.jhazmat.2007.01.126

Nure JF, Shibeshi NT, Asfaw SL et al (2017) COD and colour removal from molasses spent wash using activated carbon produced from bagasse fly ash of Matahara sugar factory, Oromiya region, Ethiopia. Water SA 43:470-479. https://doi.org/10.4314/wsa.v43i3.12

Nwabanne JT, Igbokwe P (2012) Application of response surface methodology for preparation of activated carbon from palmyra palm nut. NY Sci J 5:18-25

Sahira J, Mandira A, Prasad PB, Ram PR (2013) Effects of activating agents on the activated carbons prepared from Lapsi Seed Stone. Res J Chem Sci 3:19-24

Sailaja BK, Bhagawan D, Himabindu V, Cherukuri J (2015) Removal of fluoride from drinking water by adsorption onto Activated Alumina and activated carbon. Int J Eng Res Appl 5:19-24

Shivayogimath CB, Hiremath MN, Lokeshappa B (2008) Preparation and characterization of granular activated carbon from Acacia Nilotica Stalk by KOH activation. Int J Eng Sci Innov Technol 3:201-207

Sunday NJ, Okechukwu NS, Elom N et al (2018) Quantitative characterization of activated carbon from cow, donkey, chicken and horse bones from Ezzangbo in Ebonyi State, Nigeria. Am J Appl Chem 6:169-174. https:// doi.org/10.11648/j.ajac.20180605.12

Suneetha M, Sundar BS, Ravindhranath K (2015) Removal of fluoride from polluted waters using active carbon derived from barks of Vitex negundo plant. J Anal Sci Technol 6:1-19. https://doi.org/10.1186/s4054 3-014-0042-1

Tezcan U, Ates F, Erginel N et al (2015) Adsorption of disperse orange 30 dye onto activated carbon derived from Holm Oak (Quercus Ilex) acorns: a 3 k factorial design and analysis. J Environ Manage 155:89-96. https://doi. org/10.1016/j.jenvman.2015.03.004

UN-Water (2003) Water for people water for life. The United Nations World Water development Report 36. https://doi.org/10.1017/cbo9781107 415324.004

UN-Water (2015) Water for a sustainable world, The United Nations World water development Report 2015 Report WATER

UN Water (2018) Nature-based solutions for water, The United Nations World water development Report 2018 Report

Vardhan CMV, Srimurali M (2016) Removal of fluoride from water using a novel sorbent lanthanum-impregnated bauxite. SpringerPlus 5:1-18. https:// doi.org/10.1186/s40064-016-3112-6

World Health Organisation (2017) Guidelines for drinking water quality. World Health Organisation, Geneva

\section{Publisher's Note}

Springer Nature remains neutral with regard to jurisdictional claims in published maps and institutional affiliations. 